\title{
IDENTIFICAÇÃO DAS ÁREAS DE PRESERVAÇÃO PERMANENTE NO MUNICÍPIO DE SANTARÉM, ESTADO DO PARÁ, BRASIL, A PARTIR DE TÉCNICAS DE GEOPROCESSAMENTO
}

\author{
Identification of Areas of Permanent Preservation in the Municipality of \\ Santarém, Para State, Brazil, from Geoprocessing Techniques
}

\author{
Simmon Viegas \\ Universidade Federal do Oeste do Pará - UFOPA \\ simmonviegass@gmail.com \\ Rodolfo Maduro Almeida \\ Universidade Federal do Oeste do Pará - UFOP \\ amazonida@gmail.com \\ Felipe de Souza e Souza \\ Universidade Federal do Oeste do Pará - UFOP \\ felipy itb@hotmail.com
}

\begin{abstract}
RESUMO: O objetivo aqui proposto é identificar as áreas de preservação permanente do município de Santarém, tendo como base o Código Florestal Brasileiro e a resolução 303 do Conselho Nacional de Meio Ambiente (CONAMA). Para tanto, foram utilizados dados do modelo digital de elevação Shuttle Radar Topography Mission (SRTM), dados de sensoriamento remoto orbital do satélite Landsat-5/TM e rede de drenagem da cidade. A pesquisa consistiu em extrair os topos de morros, encostas, nascentes e cursos d'água, realizar a classificação supervisionada do uso e ocupação da área urbana de Santarém a partir de imagens orbitais e comparar o uso e ocupação de área urbana da cidade com APP's identificadas, afim de fornecer subsídios para o planejamento da expansão de ocupação urbana no município. As análises dos resultados mostraram áreas de maior atenção para o planejamento de ações que visem conter o avanço das intervenções antrópicas sobre as APP's, evidenciando que estas informações importantes para o planejamento e ordenamento territorial da área urbana do município de Santarém.
\end{abstract}

Palavras-chave: Planejamento Ambiental, Geoprocessamento, Áreas de Preservação Permanente.

ABSTRACT: The objective here is to identify the permanent preservation areas of the municipality of Santarém, based on the Brazilian Forest Code and Resolution 303 of the National Environment Council (CONAMA). In order to do so, we used digital elevation model data from the Shuttle Radar Topography Mission (SRTM), orbital remote sensing data from the LandSat-5/TM satellite and the city drainage network. The research consisted of extracting the tops of hills, slopes, springs and water courses, performing the supervised classification of the use and occupation of the urban area of Santarém from orbital images and compare the use and occupation of urban area of the city with APPs identified in order to provide subsidies for planning the expansion of urban occupation in the municipality. The analysis of the results showed areas of greater attention for the planning of actions that aim to contain the advance of anthropic interventions on the PPA's, evidencing that this important information for the planning and territorial planning of the urban area of the municipality of Santarém.

Key-words: Environmental Planning, Geoprocessing, Permanent Preservation Areas.

\section{INTRODUÇÃO}

O grande desafio das políticas públicas reside na sua efetividade. No caso específico da política urbana, a efetividade das ações das políticas setoriais de habitação, 
IDENTIFICAÇÃO DAS ÁREAS DE PRESERVAÇÃO PERMANENTE NO MUNICÍPIO DE SANTARÉM, ESTADO DO PARÁ, BRASIL, A PARTIR DE TÉCNICAS DE GEOPROCESSAMENTO
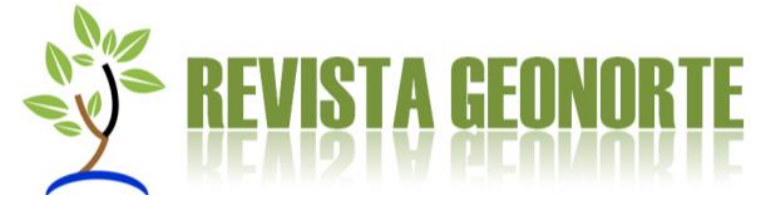

saneamento básico e transporte urbano dependem diretamente de um ambiente legal eficiente, de acordo com as características socioeconômicas da população, consideradas suas condições ambientais (MOTTA e PÊGO, 2013). A construção do espaço urbano exige intervenções na paisagem e altera drasticamente boa parte de sua biodiversidade.

O rápido crescimento das cidades faz com que os problemas ambientais sejam cada vez mais frequentes e reflitam de forma negativa na qualidade de vida de grande parte da população urbana. Desta forma, está entre as iniciativas governamentais mais propícias, a criação de leis que regem o uso de recursos e ocupação de áreas naturais. Porém, com as dimensões do espaço territorial brasileiro e a insuficiência de infraestrutura necessária para a fiscalização destas áreas, em alguns casos as leis criadas para a preservação ambiental não são cumpridas em sua totalidade.

Em contrapartida, a partir do uso do Sistema de Informação Geográfica (SIG) é demonstrado que o reconhecimento destas áreas de preservação, em grandes extensões territoriais, não é mais a maior dificuldade para que se possa cumprir o que regem as leis ambientais brasileiras, visto que o SIG visto que o SIG nos permite analisar informações espaciais da qualquer parte da superfície terrestre. Por isso estas áreas hoje se tornaram objeto de estudos que buscam encontrar soluções para amenizar os problemas causados por essa rápida expansão.

Uma importante ferramenta criada para contribuir na melhoria das condições ambientais nas cidades são as áreas de preservação permanentes (APP) (BRASIL, 2002), que são formações vegetais ao longo dos rios, as chamadas matas ciliares, e suas nascentes e áreas de morros e montanhas, além de locais com declividades definidas por lei, essas que são frágeis e que são intensamente degradadas pela urbanização. As APP's têm papel fundamental na perpetuação da biodiversidade e no abastecimento hídrico, além de se apresentar como um importante mecanismo para melhoria da qualidade do ar, de regulação das médias térmicas e para redução dos casos de alagamentos em áreas urbanas (RICETO, 2010).

Na porção oeste do Estado do Pará, a cidade de Santarém vem crescendo por ter um porto de carga para exportação graneleira e por ter se tornado centro comercial nesta região. Esses fatores podem ter influenciado o crescimento populacional da cidade, o que pode ter causado adensamento populacional e expansão da mancha urbana da cidade em direção que, por sua vez, é composta por ambientes naturais, que contém fauna e flora rica, típica da região amazônica. Furtado e Macêdo (2006) dizem que no encontro do Rios Tapajós com a margem direita do Rio Amazonas está localizada a cidade de Santarém, sendo esta considerada microrregião do médio Amazonas Paraense, sede do município de Santarém.

De posição geográfica privilegiada Santarém se beneficia do entreposto comercial do Tapajós e do Médio Amazonas, dado a sua característica de cidade, que se destaca como um dos principais portos fluviais do Amazonas e ponto de passagem entre as capitais Manaus e Belém, assim considerada a cidade mais importante desta região. Em função destas transformações que ensejaram o grande crescimento demográfico e a expansão de seu sítio urbano é indiscriminada a expansão da mancha urbana sobre sua vasta e rica fauna amazônica o que acarreta, em alguns casos, o não 
IDENTIFICAÇÃO DAS ÁREAS DE PRESERVAÇÃO PERMANENTE NO MUNICÍPIO DE SANTARÉM, ESTADO DO PARÁ, BRASIL, A PARTIR DE TÉCNICAS DE GEOPROCESSAMENTO

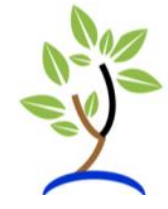

cumprimento do Código Florestal, que por sua vez estabelece a manutenção das Áreas de Preservação Permanente.

Definidas pelo Código Florestal Brasileiro de 1965, instituído pela lei n 4.771/65, as Áreas de Preservação Permanente (APP) representam locais de grande risco quanto a possíveis impactos ambientais (erosão, lixiviação, inundação, etc.). Conforme itens dos artigos $2^{\circ}$ e $3^{\circ}$ da resolução no 303 do código florestal brasileiro (BRASIL, 2002), as categorias de APP estão definidas como terço superior dos morros, as encostas com declividade superior a 45 graus, as nascentes, margens dos cursos d'água e terço superior das sub-bacias (MORAIS \& SANTOS, 2007).

As áreas de Preservação Permanentes são patrimônio da sociedade, sendo de fundamental importância zelar para que não sejam degradados. Os órgãos ambientais públicos e privados auxiliam nesse processo de defesa ao meio ambiente com implantação de leis e projetos que tem como objetivo proporcionar melhor interação entre o homem e meio ambiente. A importância de implantação de leis que protegem as Áreas de Preservação Permanente torna-se essencial quando são analisados os impactos atuais como consequência do passado, tendo em mente as gerações futuras como dependentes do hoje (LUZ, 2010).

A definição e criação das APP's visa manter inalterado o uso do solo, este que deve estar coberto sempre por sua vegetação original. De forma geral, os debates em relação a preservação e conservação da vegetação nativa merecem destaque, sobretudo aquela situada ao longo dos cursos d'água, ao longo de nascentes e em regiões de topografia acidentada, sendo estes, um dos pilares para técnicos e pesquisadores que preconizam a sua importância para proteção dos recursos hídricos. O Brasil, sendo um país de dimensões continentais, é extremamente importante que exista a representação e caracterização das APP's em mapas, já que auxilia no planejamento territorial, na fiscalização e ações de campo, sejam elas em âmbito local, regional ou nacional (HOTT et al., 2005). Portanto, o objetivo aqui proposto é identificar as Áreas de Preservação Permanente definidas pelo código florestal, na cidade de Santarém, utilizando ferramentas de geotecnologias para obter informações acerca da localização das APP's e da distribuição da ocupação urbana no município.

A área de estudo (Figura 1) está situada no município de Santarém localizado no Oeste do Estado do Pará e seus limites foram definidos conforme os centros urbanos da região, que são a área urbana de Santarém e a Vila Balneário Alter do Chão, visto que as tendências de expansão da mancha urbana ocorrem exatamente nestes dois centros populacionais. 
IDENTIFICAÇÃO DAS ÁREAS DE PRESERVAÇÃO PERMANENTE NO MUNICÍPIO DE SANTARÉM, ESTADO DO PARÁ, BRASIL, A PARTIR DE TÉCNICAS DE GEOPROCESSAMENTO
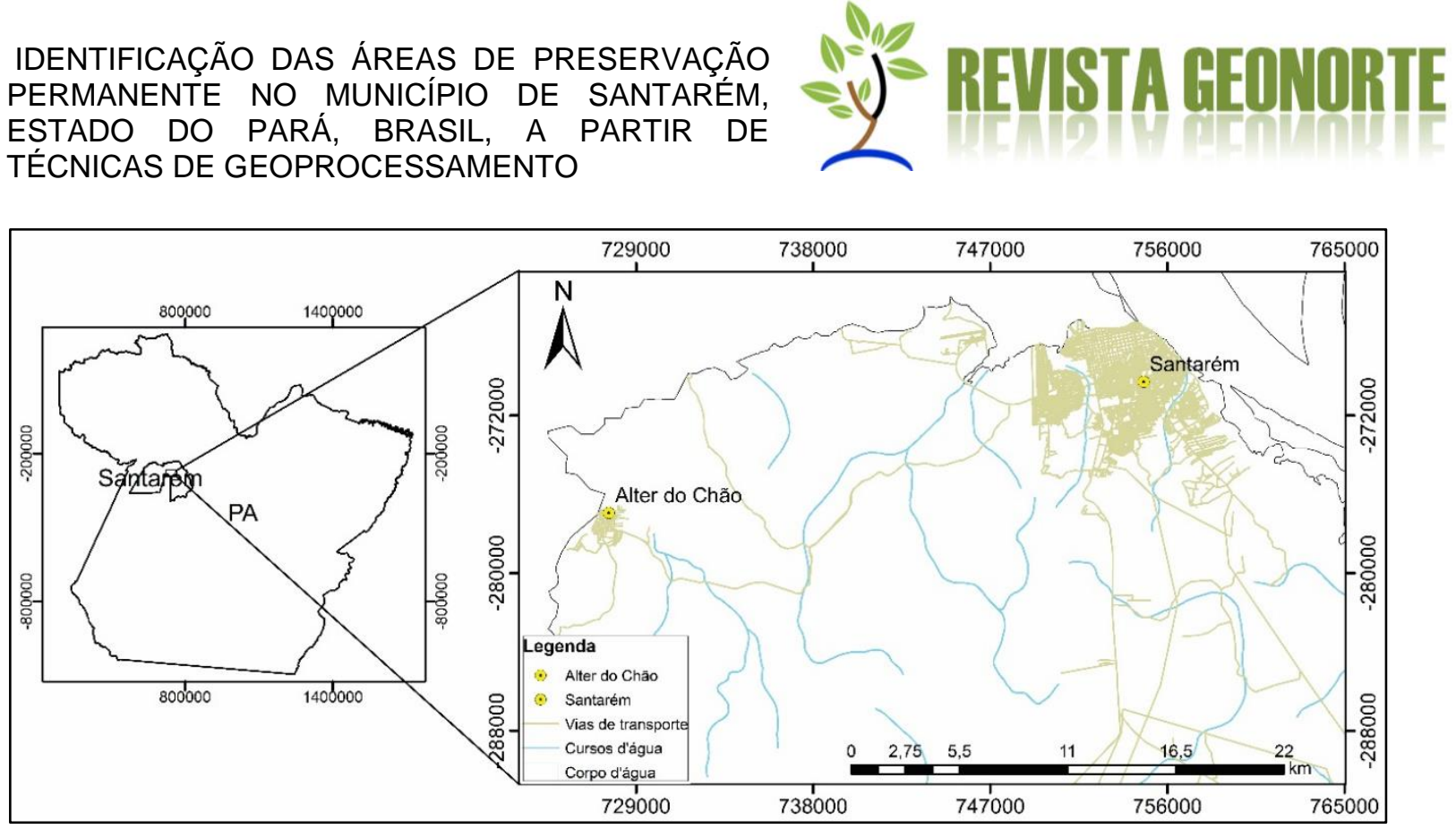

Figura 1 - Localização da área de estudo. Fonte: Autores.

\section{APP de terço superior de morro e declividade}

Serigatto (2006), diz que, de acordo com a Legislação Ambiental atual, as áreas com de terço superior do morro devem ser mantidas com sua vegetação nativa. No caso de terem sofrido atividades antrópicas, deve ser feita a recomposição da vegetação destas áreas. Essas áreas quando são mantidas com sua vegetação nativa, contribuem para a biodiversidade e para o fluxo gênico, além de, também serem responsáveis pela conservação do solo, impedindo diretamente em possíveis deslizamentos de grandes impactos e atenuando as enxurradas, favorecendo maior penetração de água no solo.

As diversas funções ambientais das Áreas de Preservação Permanente de topos de morro, montanhas e serras são vistas, também, como fundamentais para a preservação dos processos ecológicos essenciais para seu efeito conjunto (efeitos cumulativos e sinérgicos) no âmbito da bacia hidrográfica como um todo. Uma das funções desta APP é o seu papel regulador do ciclo hidrológico e sua interferência em processos como infiltração e escoamento superficial das águas, tanto em áreas urbanas como rurais (VARJABEDIAN, 2013).

O Código Florestal Brasileiro (BRASIL, 2012), estabelece os parâmetros considerados para a delimitação da APP de topo de morro, como sendo áreas em topo de morros, montes, montanhas e serras, com altura mínima de 100 (cem) metros e inclinação média maior que $45^{\circ}$. O CONAMA adota, em sua Resolução $n^{\circ} 303$, a definição para APP's de topo de Morro, como sendo qualquer elevação de terreno com cota do topo em relação à base entre $50 \mathrm{~m}$ e $300 \mathrm{~m}$ e encostas com declividade superior a $30 \%$ na linha de maior declividade. 
IDENTIFICAÇÃO DAS ÁREAS DE PRESERVAÇÃO PERMANENTE NO MUNICÍPIO DE SANTARÉM, ESTADO DO PARÁ, BRASIL, A PARTIR DE TÉCNICAS DE GEOPROCESSAMENTO

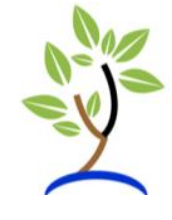

\section{APP de mata ciliar}

Segundo Serigatto (2006), mata ciliar é a vegetação nativa que ocorre ao longo dos cursos d'água, e que, é naturalmente ligada e projetada para o regime de cheias. De acordo com Hinkel (2003), a denominação desse ecossistema é altamente variada em nosso país, por causa dos diferentes ambientes de ocorrência. Nas formações arbóreas, as denominações comumente usadas são: mata ciliar, floresta de galeria, mata aluvial ou ainda mata ripária. Este termo, ripária, é considerado o mais adequado a ser aplicado a qualquer tipo vegetação relacionada ao corpo d'água e todo seu entorno. A mata ciliar é uma cobertura vegetal existente às margens das nascentes, de cursos d'água e topos de morro, demostrando fundamental importância para o controle destes ambientes, sendo considerada então, área de preservação permanente.

A preservação ou reconstituição das matas ciliares tornou-se obrigatória pela legislação de proteção ambiental brasileira, com o principal argumento de controle da erosão e melhoria de qualidade e quantidade da água. Esta APP tem grande importância, devido às raízes das árvores que a compõem ajudarem na fixação do solo às margens de cursos d'água, protegendo-o e evitando a perpetuação dos processos de erosão que ocorrem de maneira intensa nestas áreas. Além de manter estável a qualidade da água do local através da filtração de eventuais resíduos de produtos poluentes, tais como, agrotóxicos e fertilizantes, por auxiliar na recarga de aquíferos subterrâneos e por ser habitat de animais silvestres. A principal função da mata ciliar é manter a proteção das nascentes e mananciais que a margeiam.

Delitti (1989) diz que de acordo com esses aspectos, as formações ripárias têm recebido mais atenção por conta de sua distribuição peculiar, restrita às áreas que mantém contato entre os meios ambientes terrestre e aquático e lhes dá papel de extrema importância na estruturação e na dinâmica do ambiente. A grande área de proporção entre o perímetro e a área total do ecossistema, de acordo com sua posição fisiográfica, resultando num sistema profundamente mesclado e com múltiplas relações de troca com os ambientes aquático e terrestre em sua adjacência. É importante também sua participação na atenuação de forças erosivas, constantes em qualquer ambiente, na perenização dos cursos d'água e no controle da passagem de elementos essenciais do meio terrestre para o meio aquático.

\section{APP de nascentes}

De acordo com Skorupa (2003), nas áreas em que há nascentes, a vegetação local atua como uma espécie de amortecedor das chuvas, evitando que ocorra o impacto direto sobre o solo e a sua compactação. Contribui juntamente com toda a massa de raízes das plantas, que o solo permaneça com sua porosidade natural the dando capacidade de absorver a água das chuvas, alimentando os lençóis freáticos da região; evita também que o escoamento superficial excessivo de água carregue grandes quantidades de partículas de solo e/ou resíduos tóxicos, comumente provenientes de atividades agrícolas, para o leito dos cursos d'água, poluindo-os e assoreando-os. Conceitualmente, nascentes são afloramentos naturais de água com origem no lençol freático. Ao escoar pela superfície, uma nascente dá início à 
IDENTIFICAÇÃO DAS ÁREAS DE PRESERVAÇÃO PERMANENTE NO MUNICÍPIO DE SANTARÉM, ESTADO DO PARÁ, BRASIL, A PARTIR DE TÉCNICAS DE GEOPROCESSAMENTO

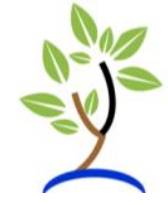

formação dos cursos d'água que por sua vez dão origem a mais cursos d'água formando então, a rede de drenagem da região. A área conhecida como bacia de contribuição para uma nascente é a localizada a montante dos cursos d'água formados.

\section{MATERIAIS E MÉTODOS}

Neste trabalho foram usadas imagens multiespectrais do satélite Landsat- 5 , sensor Thematic Mapper, dos períodos de 14/08/1986 (Composição colorida R3G4B2) e 29/06/2010 (Composição colorida R3G4B2) ambas da órbita/ponto 227/62, dados de hidrografia em formato vetorial disponibilizados pelo banco de dados do Instituto Brasileiro de Geografia e Estatística (IBGE) e um MDE da cidade de Santarém como fonte para os dados altimétricos, com 90 metros de resolução espacial, originário da missão de mapeamento do relevo terrestre SRTM (Shuttle Radar Topography Mission) disponibilizado para a América do Sul via rede mundial de computadores pela USGS Eros Data Center (Centro de Dados do Departamento de Levantamento Geológico dos Estados Unidos). A metodologia foi realizada no software ArcGIS versão 10.1 .

Para o desenvolvimento da delimitação automática de APP's, foram abordados os termos constantes no Código Florestal Brasileiro, Lei 12.651, de 25 de maio de 2012 e Resolução do CONAMA № 303 de 20 de março de 2002 (BRASIL, 2014), através do uso e aplicação de geotecnologias e Modelagem Digital de Elevação (MDE). Os métodos deste trabalho seguiram, de forma geral, as três etapas descritas a seguir (Figura 2).

Etapa 1: Delimitação das áreas de preservação permanente de cursos d'água, nascentes, topos de morro e encostas com declividade acentuada, com informações quantitativas destas, além de gerar mapas de cada APP's

Etapa 2: Mapeamento da ocupação urbana em santarém, através de análise multitemporal de imagens de satélite, com o objetivo de que o resultado nos permita identificar as áreas que sofreram adensamento populacional ou áreas que sofreram expansão da mancha urbana gerando mapas de comparativos.

Etapa 3: Realizar a integração dos dados de APP's gerados com os resultados da expansão da mancha urbana e identificar possíveis avanços sobre as APP's, fornecendo, ao fim, um mapa final de conflito de APP's versus expansão da mancha urbana da área de estudo. 
IDENTIFICAÇÃO DAS ÁREAS DE PRESERVAÇÃO PERMANENTE NO MUNICÍPIO DE SANTARÉM, ESTADO DO PARÁ, BRASIL, A PARTIR DE TÉCNICAS DE GEOPROCESSAMENTO
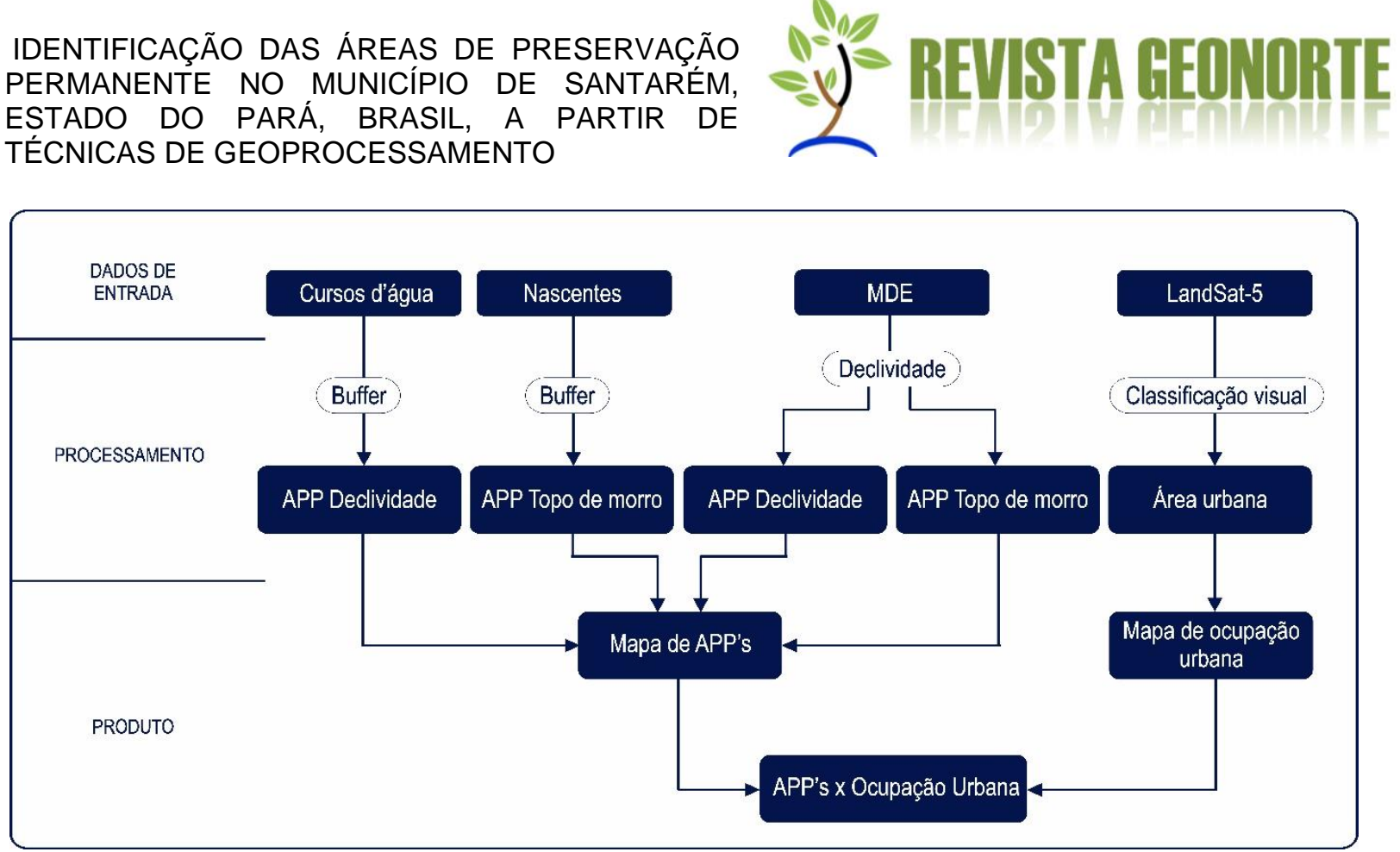

Figura 2 - Fluxograma metodológico para delimitação de APP's e mapeamento de mancha urbana. (Elaborado pelos autores).

Baseado no Código Florestal Brasileiro e Resolução CONAMA 303, foram consideras Áreas de Preservação Permanente com as seguintes características (Tabela 1).

Tabela 1 - Áreas que devem ser consideradas para a criação da APP's.

\begin{tabular}{c|c}
\hline APP & Regras segundo a legislação vigente \\
\hline Cursos d'água & Os 30 metros, para os cursos d'água de menos de 10 metros de \\
largura.
\end{tabular}

Organizado: Autores.

\section{Delimitação de APP's de topo de morros.}

A delimitação desta área de preservação permanente foi efetuada segundo a metodologia proposta por Hott, et al. (2005). Inicialmente foi necessário a conversão de toda a base de dados para o sistema de coordenadas planas, neste caso, a projeção UTM (Universal Transversa de Mercator), para possibilitar a extração das 
IDENTIFICAÇÃO DAS ÁREAS DE PRESERVAÇÃO PERMANENTE NO MUNICÍPIO DE SANTARÉM, ESTADO DO PARÁ, BRASIL, A PARTIR DE TÉCNICAS DE GEOPROCESSAMENTO

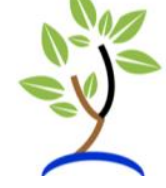

informações sobre a declividade do terreno. A delimitação da APP de topo de morro se dá através dos seguintes passos:

- Partir do MDE e realizar a extração dos pontos referentes ao topo e base dos morros da região obtendo-se a amplitude de altitude.

- Identificar as área com amplitudes maiores ou iguais a 100 metros.

- Dentre estes considerar apenas aqueles que possuem declividade superior ou igual a $25^{\circ}$.

- Delimitação o terço superior de cada morro encontrado.

A figura 3 representa um modelo hipotético de morro com base de altura 0 metros e topo com altura 100 metros. De acordo com a legislação abordada, neste exemplo, seu terço superior deve estar limitado pela cota 66,66 metros e toda a área acima desta cota deve ser considerada área de preservação permanente.

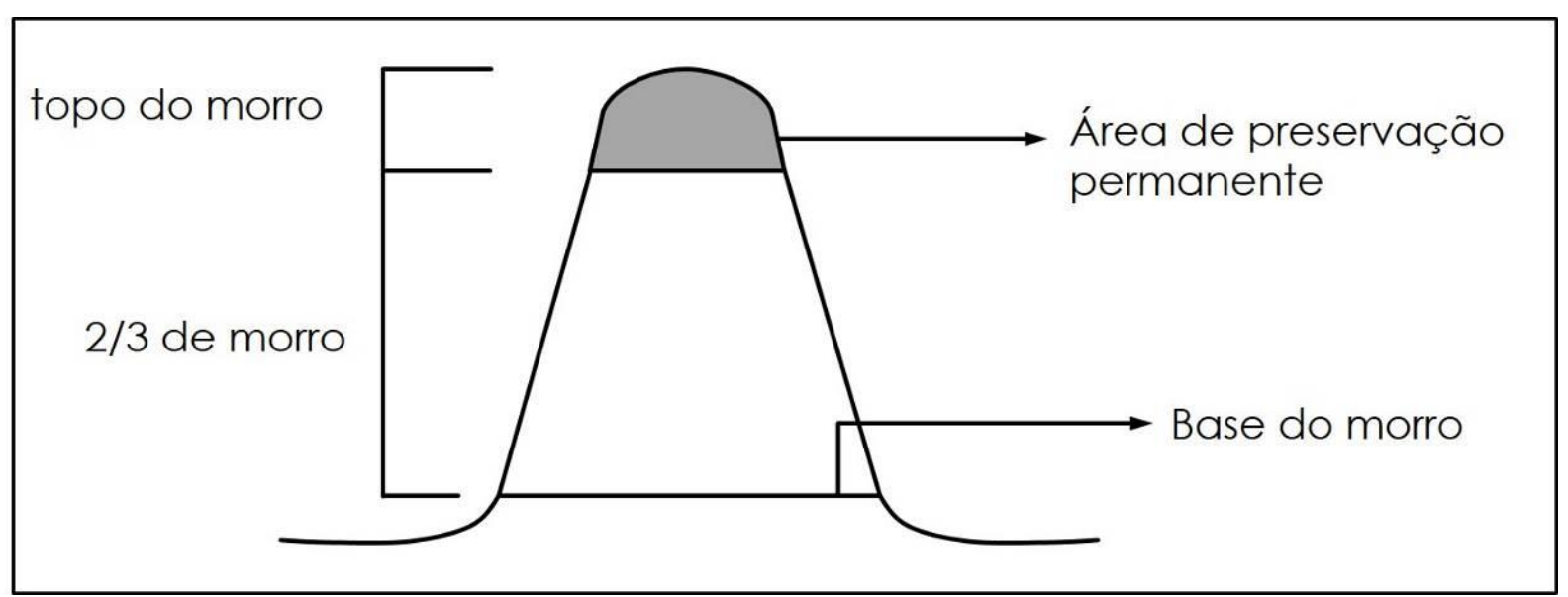

Figura 3 - Modelo hipotético de APP de topo de morro, serra ou montanha.

(Elaborado pelos autores).

\section{Delimitação de APP's de Declividade}

A delimitação de APP de declividade é obtida a partir do Modelo Digital de Elevação e das informações de declividade. Durante o processamento é definido que a interpolação deve basear-se em uma declividade de $45^{\circ}$ (equivalente a $100 \%$ ) e assim é realizada a reclassificação todos os valores para a identificação das prováveis APP'S de declividade.

\section{Delimitação de APP's de nascentes e cursos d'água}

Nessa etapa, as nascentes foram extraídas a partir dos cursos d'água do banco de dados do IBGE, considerando que em cada extremidade de curso d'água há uma nascente. A delimitação das áreas de preservação no entorno das nascentes e cursos d'água foi realizada utilizando a ferramenta buffer, que é uma forma de análise de proximidade onde zonas de um objeto são delimitadas em seu entorno. De acordo 
IDENTIFICAÇÃO DAS ÁREAS DE PRESERVAÇÃO PERMANENTE NO MUNICÍPIO DE SANTARÉM, ESTADO DO PARÁ, BRASIL, A PARTIR DE TÉCNICAS DE GEOPROCESSAMENTO

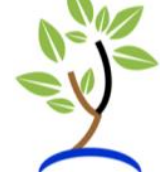

com esta ferramenta é estipulado o raio de preservação da APP, neste caso, um raio de 50 metros no entorno das nascentes e 30 metros para os cursos d'água. Na figura 4 estão ilustrados exemplos da área de APP' dos cursos d'água e nascentes.

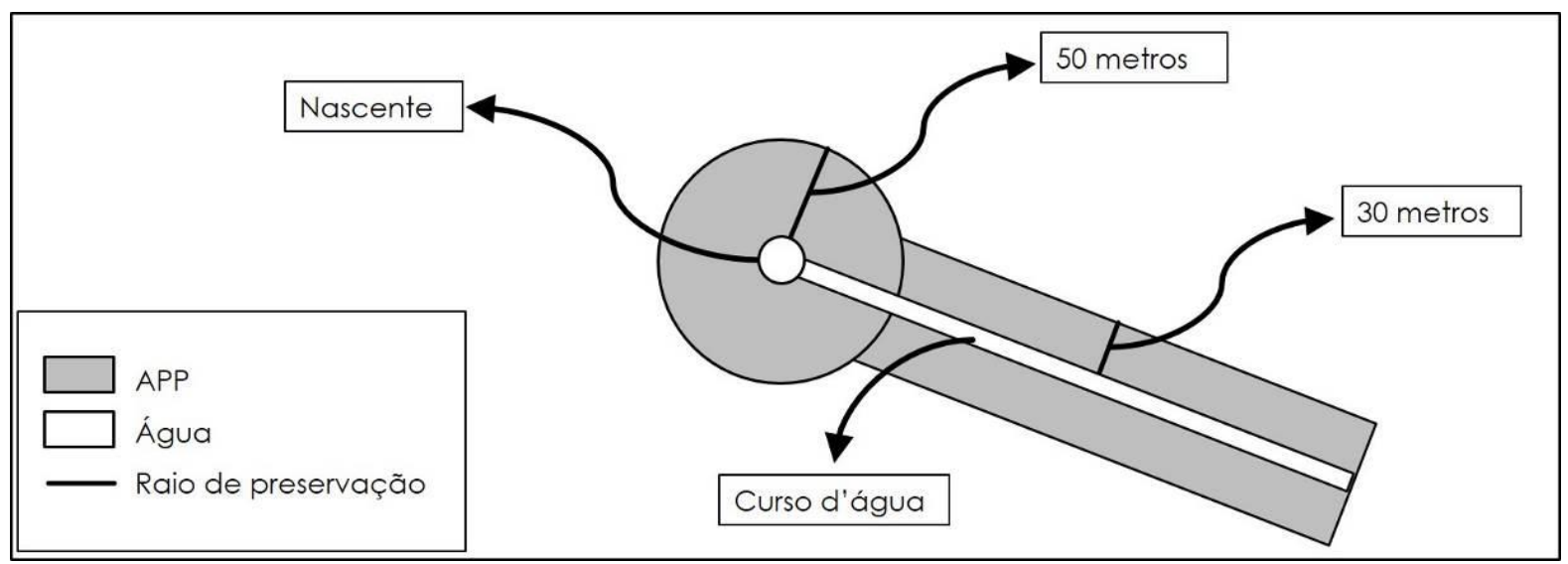

Figura 4 - Esquema para identificação de APP's de nascentes e cursos d'água, de acordo com os critérios estabelecidos pela legislação. (Elaborado pelos autores).

\section{Mapeamento da ocupação urbana}

O mapeamento da mancha urbana no entorno de Santarém e Alter do Chão foi feito a partir de interpretação visual das duas imagens Landsat-5 de dois períodos distintos (anos 1986 e 2010) com o auxílio do módulo editor no software ArcGIS com o propósito de identificar possíveis aumentos da área urbana. Por fim, foi feito o cálculo de área de cada classificação para comparação quantitativa das informações geradas.

\section{RESULTADOS E DISCUSSÕES}

\section{Delimitação das áreas de preservação permanente}

A metodologia de delimitação automática das áreas de preservação permanente que teve como referência legal o Código Florestal Brasileiro e a resolução 303 do Conselho Nacional de Meio Ambiente possibilitou a identificação e quantificação das categorias de APP's da área estudada representadas na escala 1:150.000. APP's identificadas: Terço superior de morro, curso d'água e nascentes.

\section{Áreas de preservação permanente com declividade.}

De acordo com o mapa de declividade (Figura 5) a área de estudo possui relevo com declividade inferior a $100 \%$, o que representa $45^{\circ}$ de inclinação e, por este motivo, não foram identificadas áreas de preservação permanente de encostas. 
IDENTIFICAÇÃO DAS ÁREAS DE PRESERVAÇÃO PERMANENTE NO MUNICÍPIO DE SANTARÉM, ESTADO DO PARÁ, BRASIL, A PARTIR DE TÉCNICAS DE GEOPROCESSAMENTO

\section{Oy' REVISTA GEONORTE}

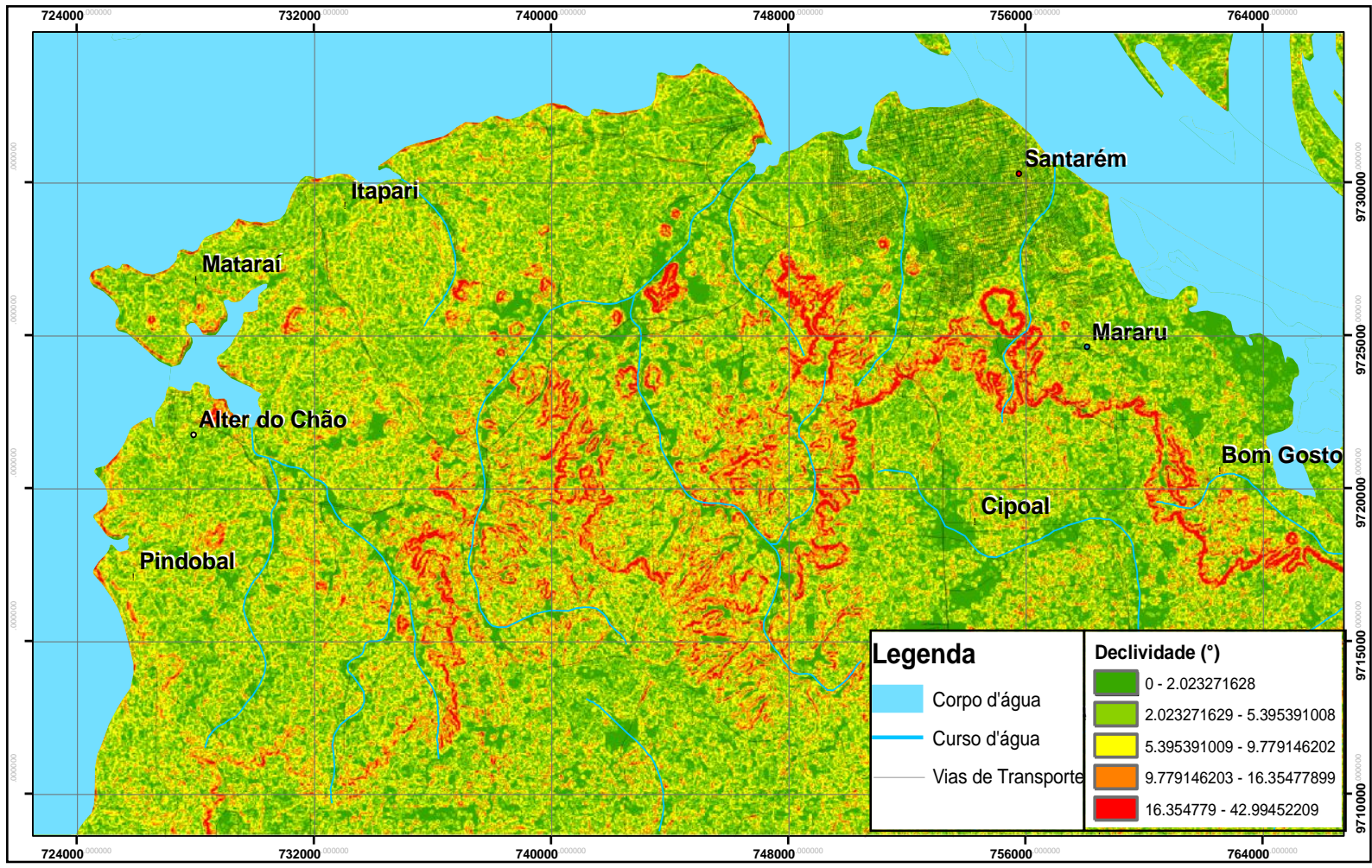

Figura 5 - Mapa APP's de declividade. Fonte: Autores.

O modelo digital de elevação possui resolução espacial de 90 metros, ou seja, nos intervalos entre cada célula digital da imagem há a possibilidade de haver APP's de declividade, o que pode ser o motivo de não ser identificada nenhuma área de preservação permanente com declividades iguais ou maiores a $45^{\circ}$ de inclinação. Outro motivo é que a metodologia proposta não seja eficiente em casos de maiores detalhes ou até mesmo que realmente não exista áreas com declividades superiores $45^{\circ}$.

\section{Áreas de preservação permanente em topos de morro, montanhas e serras.}

As áreas de preservação permanente em topo de morros, serras e montanhas totalizaram uma área de $2,481 \mathrm{~km}^{2}$, representando $20,34 \%$ do total de APP's identificadas na área de estudo. O mapa da figura 6.A) mostra a localização das APP's de topo de morro, serras e montanhas. As figuras 6.B) e 6.C) representam as áreas com maior concentração das APP's identificadas e que mantêm maior proximidade com a área urbana da cidade de Santarém. 
IDENTIFICAÇÃO DAS ÁREAS DE PRESERVAÇÃO PERMANENTE NO MUNICÍPIO DE SANTARÉM, ESTADO DO PARÁ, BRASIL, A PARTIR DE TÉCNICAS DE GEOPROCESSAMENTO

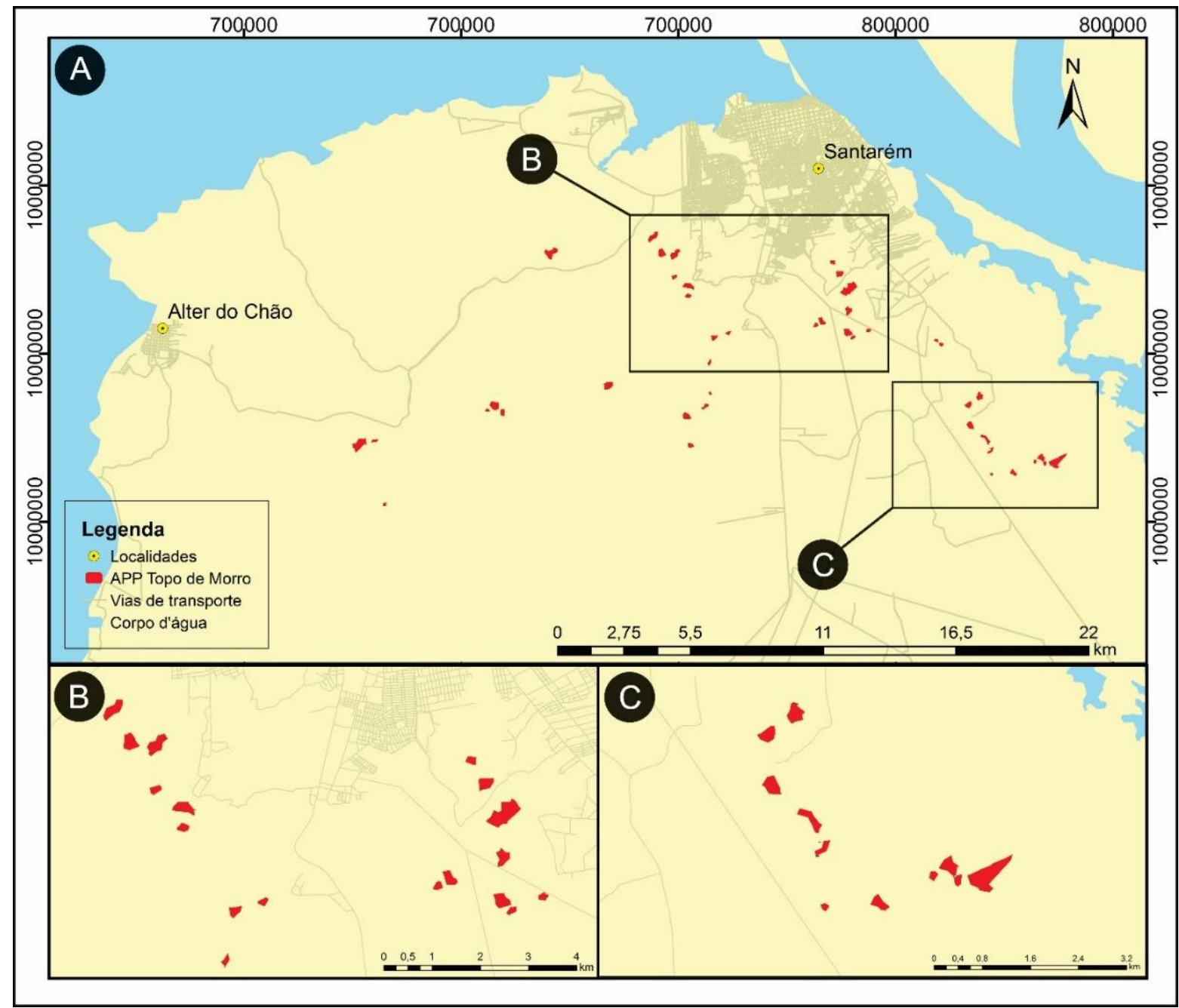

Figura 6 - A) Mapa de APP's em topos de morros, montanhas e serras identificadas. B) Detalhe das APP's identificadas próximo a grande área do Bairro do Santarenzinho. C) Detalhe das APP's próximas da rodovia Curuaúna. (Elaborado pelos autores).

A área da figura 6.B se enquadra na região dos bairros identificados como Grande Área da Nova República e Grande Área do Santarenzinho, que contêm intenso adensamento populacional e crescimento espacial em suas periferias. A figura 6.C detalha a área da rodovia estadual Curuaúna, que liga a cidade com a Hidrelétrica de Curuaúna que também demonstra crescimento de comunidades e vilas às suas margens.

\section{Áreas de preservação permanente ao redor de nascentes e ao longo de cursos d'água.}

As áreas de preservação permanente ao redor de nascentes totalizam uma área de $0,118 \mathrm{~km}^{2}$, representando $0,963 \%$ do total de APP's. Já as APP's de curso d'água identificadas apresentam grande representatividade na área, totalizando $9,597 \mathrm{~km}^{2}$, representando $78,693 \%$ do total de APP's. Os resultados da delimitação das APP's de nascentes e cursos d'água estão nas figuras 7 e 8. 
IDENTIFICAÇÃO DAS ÁREAS DE PRESERVAÇÃO PERMANENTE NO MUNICÍPIO DE SANTARÉM, ESTADO DO PARÁ, BRASIL, A PARTIR DE TÉCNICAS DE GEOPROCESSAMENTO
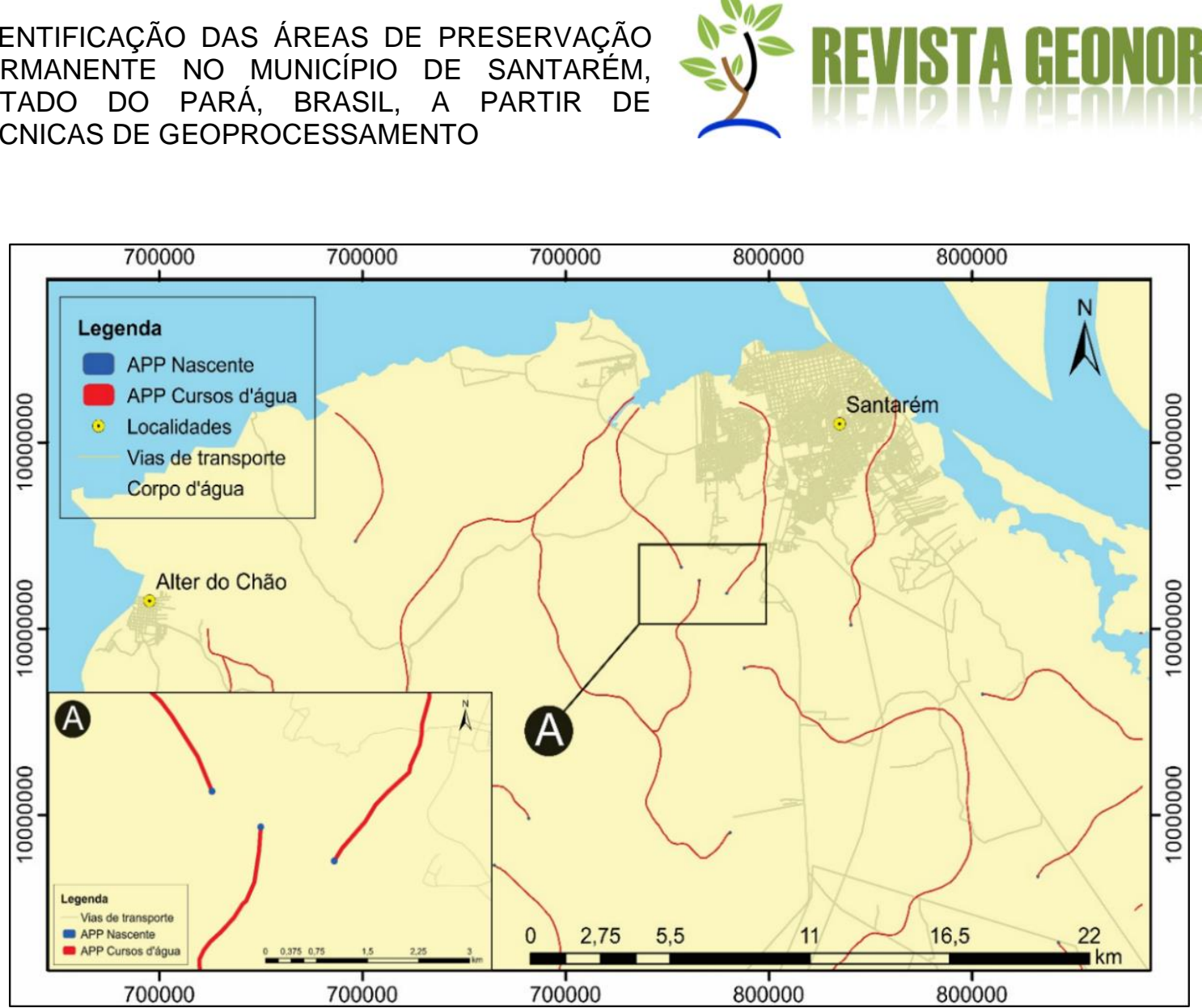

Figura 7 - Mapa de APP's de cursos d'água e nascentes identificadas. Detalhe das APP's identificadas próximo da área urbana de Santarém. (Elaborado pelos autores).

\section{Conjunto de dados das áreas de preservação permanente}

A área de estudo apresenta uma área de $12,196 \mathrm{~km}^{2}$ de áreas de preservação permanente, sendo que a área de preservação permanente que possui maior área é a APP de cursos d'água, o que pode ser explicado pelo falo de a área estar contida, principalmente, nas classes geomorfológicas da Planície Amazônica e no Planalto Rebaixado da Amazônia, que mantém características de intensa rede de drenagens e áreas alagadiças. A tabela 2 mostra as categorias de áreas de preservação permanente identificadas e suas respectivas áreas em $\mathrm{km}^{2}$, além das representatividades, em porcentagem, de cada APP.

Tabela 2 - Quantificação da área total das áreas de preservação permanente identificadas na área de estudo.

\begin{tabular}{c|c|c}
\hline Categoria de APP & Área total das APP $\left.\mathbf{( k m}^{2}\right)$ & Porcentagem em relação ao total de APP's (\%) \\
\hline Topo de morro & 2,481 & 20,345 \\
\hline Nascente & 0,118 & 0,963 \\
\hline Curso d'água & 9,597 & 78,692 \\
\hline Declividade sup. $45^{\circ}$ & 0 & 0 \\
\hline Total & 12,196 & 100 \\
\hline
\end{tabular}

Fonte: Autores. 
IDENTIFICAÇÃO DAS ÁREAS DE PRESERVAÇÃO PERMANENTE NO MUNICÍPIO DE SANTARÉM, ESTADO DO PARÁ, BRASIL, A PARTIR DE TÉCNICAS DE GEOPROCESSAMENTO

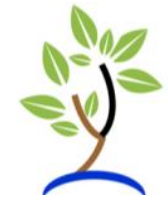

\section{Mapeamento da ocupação da área urbana de Santarém.}

O mapeamento da área urbana de Santarém permitiu a identificação e quantificação das áreas urbanas nos principais centros urbanos da área. Realizando a comparação entre as figuras 09.A) e 09.B), podemos observar a diferença entre as áreas urbanas de 1986 e 2010, com destaque para a expansão da mancha urbana de Santarém.

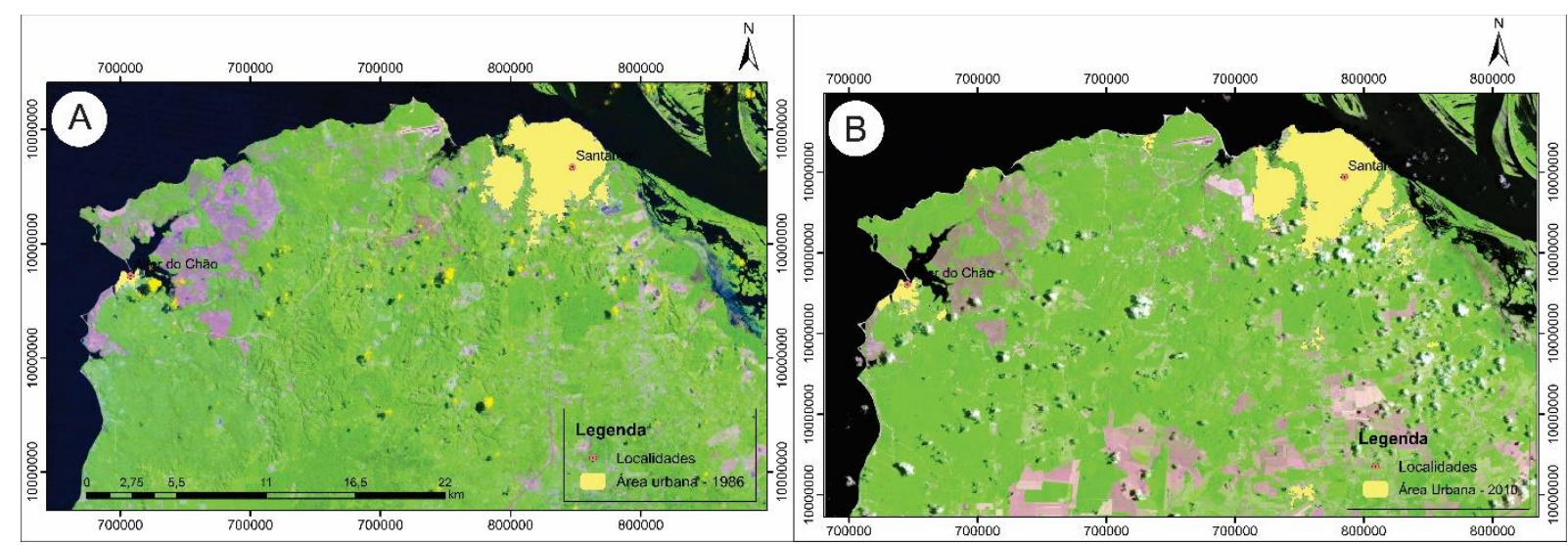

Figura 8 - Mapeamento da ocupação urbana da área de estudo nos anos de A) 1986 e B) 2010. (Elaborado pelos autores).

Na mancha urbana da imagem no ano de 1986 (Figura 9.A) são observados três polígonos, sendo um maior, centralizado e outros dois, bem menores ao extremo do primeiro. A mancha urbana de 2010 (Figura 9.B) apresenta também três polígonos, com diferenças de crescimento visível, se comparado à imagem de 1986. Esta diferença se dá tanto no polígono central quanto nos localizados nas extremidades, além de apresentar outros polígonos menores em área mais afastadas, por exemplo, na vila de Alter do Chão. A figura 10 faz a comparação da mancha urbana no município entre os anos citados, mostrando o crescimento no intervalo de 24 anos. 
IDENTIFICAÇÃO DAS ÁREAS DE PRESERVAÇÃO PERMANENTE NO MUNICÍPIO DE SANTARÉM, ESTADO DO PARÁ, BRASIL, A PARTIR DE TÉCNICAS DE GEOPROCESSAMENTO

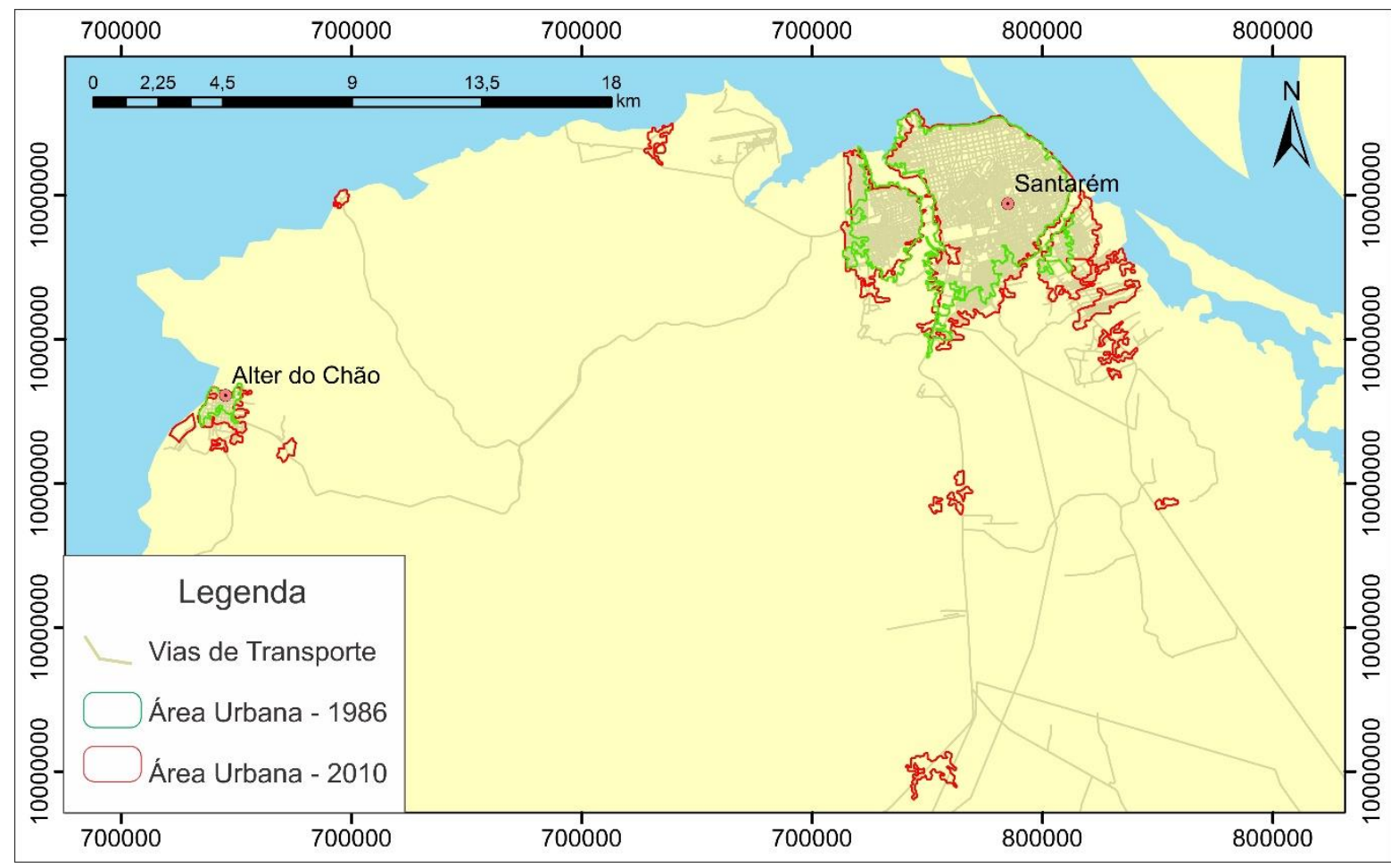

Figura 9 - Comparação do crescimento da mancha urbana entre os anos de 1986 e 2010. (Elaborado pelos autores).

A tabela 3 mostra o a área urbana total do município e sua taxa de crescimento, onde, entre o ano de 1986 e 2010, houve um acréscimo/crescimento de aproximadamente $14 \mathrm{~km}^{2}$ ou $41,85 \%$ de área urbana. Crescimento este que se deu principalmente ao longo da rodovia Engenheiro Fernando Guilhon, que liga Santarém a vila de Alter do Chão, onde estão localizados os bairros do Santarenzinho e Maracanã.

Tabela 3 - Quantificação da área urbana e porcentagem de crescimento.

\begin{tabular}{c|c|c}
\hline Ano & Área urbana $\left.\mathbf{( k m}^{\mathbf{2}}\right)$ & Percentual em relação a área urbana total (\%) \\
\hline 1986 & 33,019 & 41,35 \\
\hline 2010 & 46,838 & 58,65 \\
\hline Total & 79,85 & 100 \\
\hline
\end{tabular}

\section{Comparação do uso e ocupação com a delimitação das APP's.}

Os critérios relativos às delimitações de faixas marginais de rios, entorno de nascentes e topos de morros, montanhas e serras foram agrupados em um único plano de informação, gerando um mapa final de Áreas de Preservação Permanente (APP) sobreposto a área urbana da cidade de Santarém, compatível com a escala 1:150.000 (Figura 11). 
IDENTIFICAÇÃO DAS ÁREAS DE PRESERVAÇÃO PERMANENTE NO MUNICÍPIO DE SANTARÉM, ESTADO DO PARÁ, BRASIL, A PARTIR DE TÉCNICAS DE GEOPROCESSAMENTO
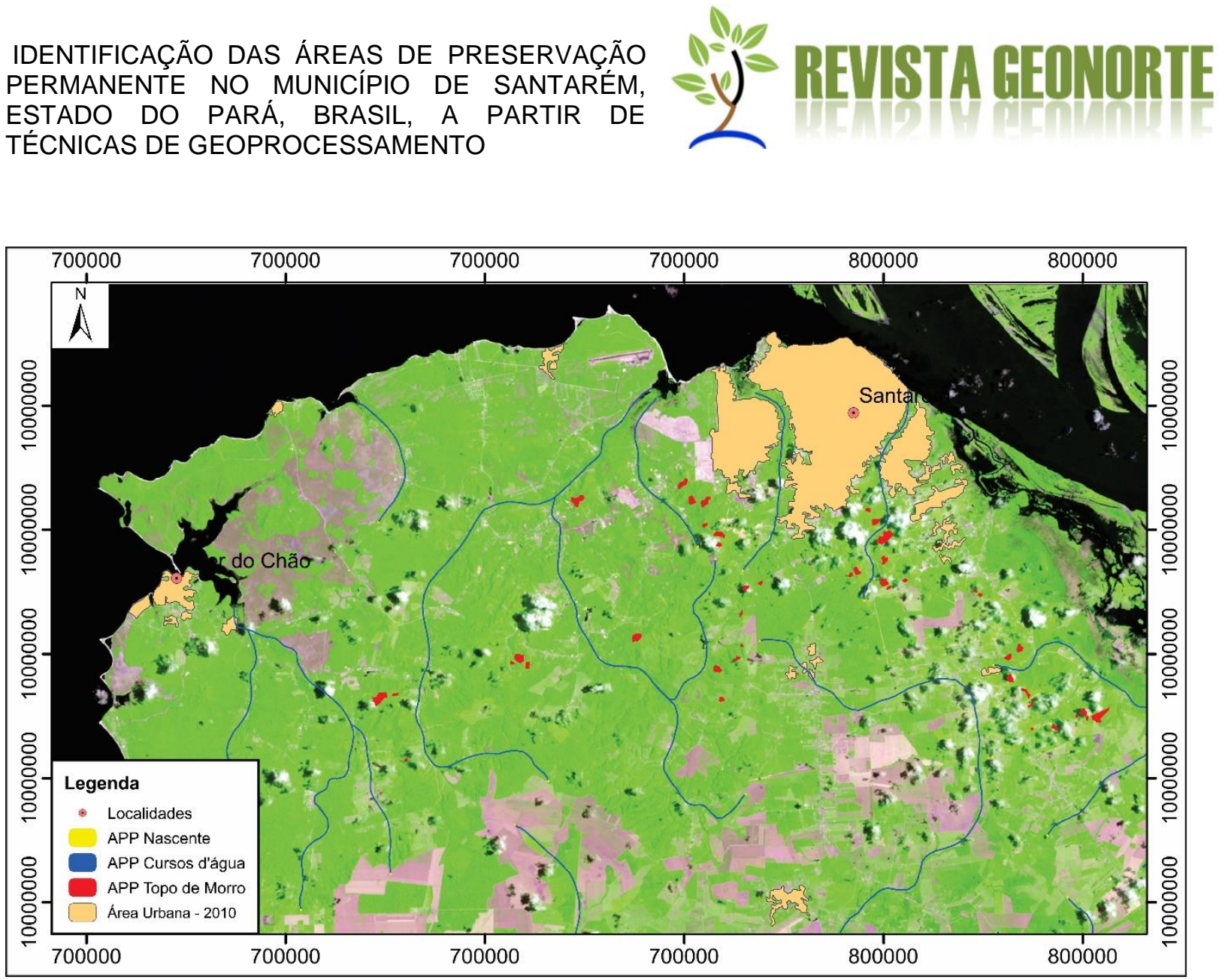

Figura 10 - Sobreposição das áreas de preservação permanente com a mancha urbana da área de estudo. Fonte: Autores.

Baseado na análise temporal entre as figuras 09.A) e 09.B), é possível que a tendência é que a área urbana da cidade de Santarém se estenda ainda mais nos próximos anos e, com este crescimento, passe a ocupar partes das áreas de preservação permanente delimitadas neste trabalho. No mapa observa-se que após a notória expansão da área urbana e sua sobreposição com as APP's identificadas, se mostra possível que ocorra a aproximação desta área urbana sobre as áreas de preservação permanente.

A classe de APP que se apresenta mais suscetível a área urbana é a APP de topo de morro, pois esta, está localizada justamente na direção em que a área urbana da cidade tem maior tendência a se estender, de acordo com a análise temporal. $\mathrm{Na}$ categoria de APP de nascentes e cursos d'água, na escala do trabalho, há pouco contato entre esta APP e a área urbana da cidade, o que não indica que não há contato e intervenção humana nestas áreas.

$\mathrm{Na}$ expansão da malha urbana, é comum o problema de crescimento desordenado, sem planejamento prévio, o que permite, essencialmente, a geração de esgoto e resíduos sólidos sem tratamento e isto é um dos fatores que pode acarretar na contaminação de cursos d'água próximos a estas áreas. Portanto, é fundamental o acompanhamento destas áreas para prever seu crescimento e a previsão da forma que esse crescimento irá ocorrer, com o objetivo de encontrar soluções de 
IDENTIFICAÇÃO DAS ÁREAS DE PRESERVAÇÃO PERMANENTE NO MUNICÍPIO DE SANTARÉM, ESTADO DO PARÁ, BRASIL, A PARTIR DE TÉCNICAS DE GEOPROCESSAMENTO

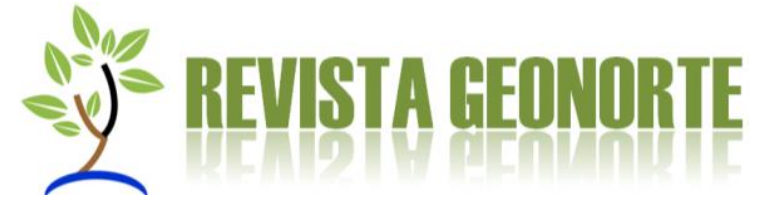

planejamento para que não haja conflito com as áreas de preservação, mas sim sua manutenção.

\section{CONSIDERAÇÕES FINAIS}

O método de delimitação automática de Áreas de Preservação Permanente empregado neste trabalho se mostrou adequado ao objetivo inicial. Áreas de Preservação Permanente em topos de morros, montanhas e serras, as nascentes e os cursos d'água foram reconhecidas para a cidade de Santarém e geradas com eficiência utilizando a ferramenta de sistema de informações geográficas.

Com o uso do SIG, foram obtidos os resultados esperados e estes resultados foram gerados com confiabilidade para serem aplicados no mapeamento de APP's e uso da ocupação urbana com o intuito de servir como base para ações de planejamento de desenvolvimento agrícola e florestal, zoneamento, ordenamento territorial e fiscalização ambiental.

O mapeamento de APP's poderá apoiar-se em critérios ecologicamente estabelecidos, contribuindo para complementar eventuais lacunas e promover a melhoria na forma e função das áreas de preservação permanente. As áreas de Preservação Permanente representam grande importância para a sociedade, e saber como interagir no meio ambiente, sem que ele sofra bruscas transformações, é uma forma de equilíbrio entre homem e o meio ambiente.

\section{REFERÊNCIAS BIBLIOGRÁFICAS}

BRASIL, MINISTÉRIO DA SAÚDE. Saúde Ambiental e Gestão de Resíduos de Serviços de Saúde. Brasília, Editora MS, 2002.

BRASIL. Resolução CONAMA $n^{\circ} 303$, de 20 de março de 2002, dispõe sobre as áreas de preservação permanente. Disponível em: http://www.mma.gov.br/. Acesso em: 22 de novembro de 2014.

DELITTI, W. B. C. Ciclagem de nutrientes minerais em matas ciliares. In: BARBOSA, L. M., coord. Anais do Simpósio sobre mata ciliar. Campinas: Fundação Cargil, 1989. p. 88.

FURTADO, A.M.M.; MACEDO, M.R.A.; As Unidades de Relevo e a Expansão do Sítio Urbano da Grande Santarém - Microrregião do Médio Amazonas Paraense - Estado do Pará: Observações Preliminares. Anais: VI Simpósio Nacional de Geomorfologia. Pará, 2006.

HINKEL, R. Vegetação ripária: funções e ecologia. Seminário de Hidrologia Florestal: Zonas ripárias, v. 1, p. 40-80, 2003.

HOTT, M. C.; GUIMARÃES, M.; MIRANDA, E. E. Um Método para a Determinação Automática de Áreas de Preservação Permanente em Topos de Morros para o Estado 
IDENTIFICAÇÃO DAS ÁREAS DE PRESERVAÇÃO PERMANENTE NO MUNICÍPIO DE SANTARÉM, ESTADO DO PARÁ, BRASIL, A PARTIR DE TÉCNICAS DE GEOPROCESSAMENTO

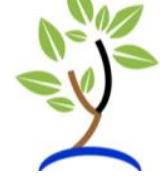

de São Paulo. In: Simpósio Brasileiro de Sensoriamento Remoto, 12, 2005, Goiânia. Anais. São José dos Campos: Inpe, 2005.

LUZ, E.F.; Área de Preservação Permanente (APP) Módulo 05 e Setor J Localizado no município de Juína/MT. Juína, 2010.

MORAIS, A. C.; SANTOS, A. R. Geomática e Análise Ambiental: Aplicações práticas. Vitória, 2007.

MOTTA, D. M.; PÊGO, B; Licenciamento Ambiental para o Desenvolvimento Urbano: avaliação de instrumentos e procedimentos. Instituto de Pesquisa Econômica Aplicada - IPEA. Rio de Janeiro, 2013.

RICETO, A. As Áreas de Preservação Permanente (APP) Urbanas: Sua Importância para a Qualidade Ambiental nas Cidades e Suas Regulamentações. Uberlândia. Universidade Federal de Uberlândia. Revista Católica. 2010.

SERIGATTO, E.M.; Delimitação de Áreas de Preservação Permanente e identificação dos conflitos de uso da terra na bacia hidrográfica do rio Sepotuba-MT. Viçosa: UFV, 2006.

SKORUPA, L.A.; Áreas de Preservação Permanente e Desenvolvimento Sustentável. Embrapa. Jaguariúna, 2003.

VARJABEDIAN, R; MECHI, A. As APP's de Topo de Morro e a Lei 12.651/12. Ministério Público do Estado de São Paulo: Rua Riachuelo, n.ำ115, $7^{\circ}$ andar, centro, São Paulo, CEP: 01007-904. 2013. 